\title{
BMJ Global Health Let food be thy medicine: linking local food and health systems to address the full spectrum of malnutrition in low- income and middle-income countries
}

\author{
Lindsay M Jaacks, Alexandra L Bellows
}

To cite: Jaacks LM, Bellows AL. Let food be thy medicine: linking local food and health systems to address the full spectrum of malnutrition in low-income and middle-income countries. BMJ Glob Health 2017;2:e000564. doi:10.1136/ bmjgh-2017-000564

Handling editor Seye Abimbola

Received 12 September 2017 Revised 13 October 2017 Accepted 18 0ctober 2017

\section{CrossMark}

Department of Global Health and Population, Harvard T.H. Chan School of Public Health, Boston, Massachusetts, USA

Correspondence to Dr Lindsay M Jaacks; jaacks@hsph.harvard.edu
Hippocrates (fifth century BCE), the father of medicine and namesake of the Oath many medical students swear by to this day, was among the first to recognise the centrality of diet in disease prevention and treatment. In that Oath, the statement, 'I will apply dietetic measures for the benefit of the sick according to my ability and judgement', comes before statements about drugs and surgery. Unfortunately, the importance of diet and nutrition in medicine is lost in most discussions of health system reform today, especially in low-income and middle-income countries (LMICs). Moreover, few food system researchers and policymakers consider the myriad opportunities for improving health through forging partnerships between local food, agriculture and health systems.

In this commentary, we highlight the potential for healthcare institutions to improve access to and adoption of healthy diets beyond providing nutrition counselling in order to address the full spectrum of malnutrition in LMICs (figure 1) and provide examples of how this framework could be implemented in LMICs. We adopt the United Nations' definitions of a food system as 'all activities related to the production, distribution and consumption of food', and of a health system as 'the people, institutions and resources, arranged together in accordance with established policies, to improve the health of the population they serve'. ${ }^{2}$ Considering the great success of extending the reach of antenatal clinics in LMICs-over $80 \%$ of women in 38 LMICs studied had at least one visit during pregnancy ${ }^{3}$ - and the anticipated increase in healthcare utilisation in LMICs as a result of expansion of universal health coverage, healthcare institutions as an intervention setting have the potential to have a substantial impact.

\section{Summary box}

Advancing universal health coverage and improving health system quality are among the most important issues faced by those engaged in global health today.

- The critical role played by a healthy food system in disease prevention and treatment is overlooked in discussions of health system reform, especially in low-income and middle-income countries.

- Forming strong links between local food and health systems may be an important point of intervention for addressing both ends of the malnutrition spectrum.

In this commentary, we highlight the potential for healthcare institutions to improve access to and adoption of healthy diets beyond providing nutrition counselling in order to address the full spectrum of malnutrition in low-income and middle-income countries.

In many LMICs struggling to address the full spectrum of malnutrition, from undernutrition to obesity and nutrition-related non-communicable diseases, the underlying problem is not one of caloric insufficiency, but rather one of poor diet quality. ${ }^{4}$ For example, in Guatemala, $50 \%$ of reproductive-aged women are overweight or obese and $48 \%$ of children under five are stunted (an indicator of chronic undernutrition). ${ }^{5}$ Prospective epidemiological studies have demonstrated a positive relationship between consumption of red meat, processed foods and sugar-sweetened beverages and risk of obesity in adults, whereas consumption of fruits, vegetables, nuts and legumes is associated with a decreased risk of obesity. ${ }^{6}$

On the other end of the malnutrition spectrum, randomised controlled trials of nutrition counselling to mothers delivered by trained healthcare providers that focuses on improving healthy complementary feeding 


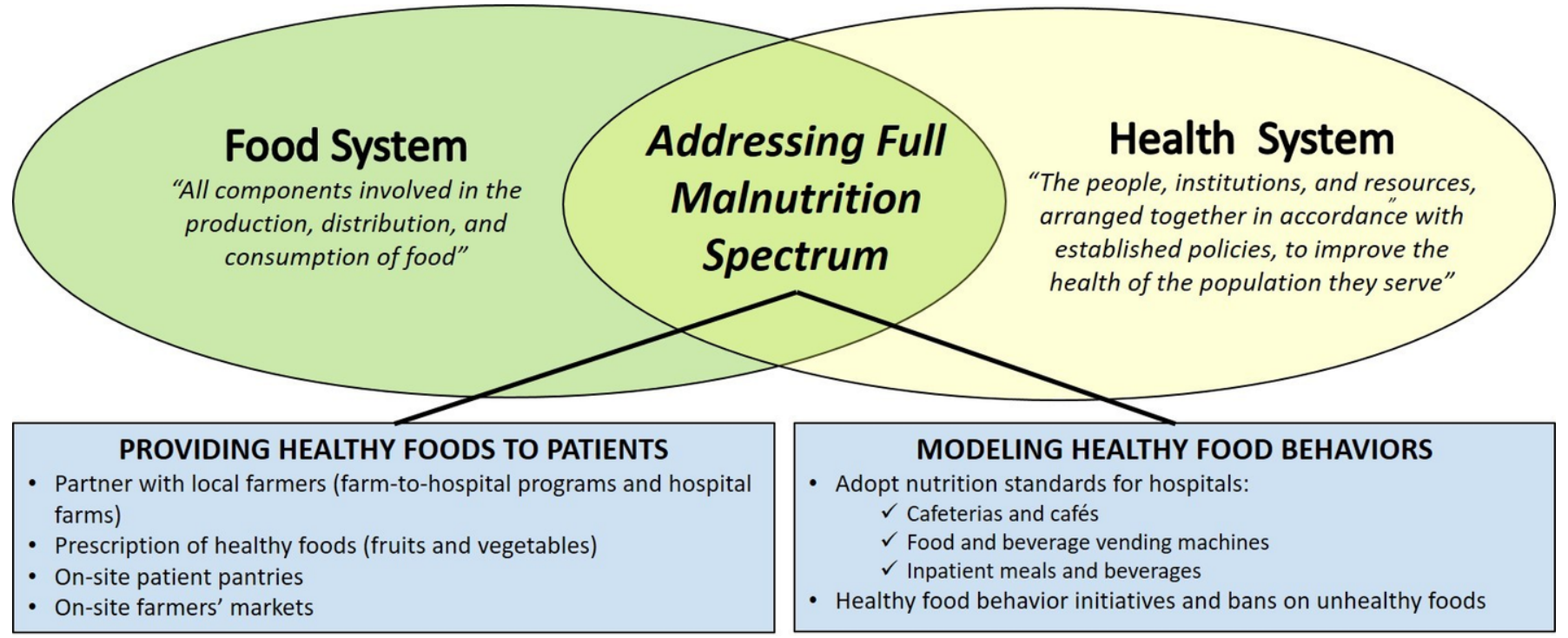

Figure 1 Conceptual framework demonstrating the intersection between local food and health systems and specific opportunities to improve overall health and address the full spectrum of malnutrition in the context of low-income and middleincome countries. Definitions of food and health systems are drawn from the Food and Agriculture Organisation and the WHO, respectively. The framework was developed based on evidence that diverse diets including fruits, vegetables, nuts, legumes and select animal-based products such as eggs can reduce the risk of stunting, micronutrient deficiencies, overweight/obesity and nutrition-related non-communicable diseases and that healthcare institution-based interventions can directly improve intake of these foods.

practices have been shown to result in a $29 \%$ reduction in stunting. ${ }^{7}$ Results from a randomised trial, published this year, found that the prevalence of stunting among Ecuadorian children (ages 6-9 months) who received one egg per day for 6 months was reduced by $47 \%$ compared with controls. ${ }^{8}$ Few studies have explicitly evaluated both ends of the malnutrition spectrum. One ecological study found that a $100 \mathrm{kcal}$ increase (per capita per day) in availability of vegetables was associated with a reduction in heart disease mortality of 459 per 100000 population among adults $>55$ years and a $3.5 \%$ lower stunting rate among children. ${ }^{9}$ Based on this evidence, our proposed actions for healthcare institutions involve the promotion of a whole food-based diet including fruits, vegetables, nuts, legumes and healthy, environmentally sustainable animal-based products such as eggs instead of meat.

The first step towards initiating improvements in healthcare institution food environments is the adoption of mandatory nutrition standards for patient meals, cafeterias and vending machines. The Healthy Hospital Food Initiative in New York City demonstrated that the adoption of such standards can result in improvements in the healthfulness of food offerings in this setting. ${ }^{10}$ Internationally, the Healthy Food in Healthcare Pledge, part of Healthcare Without Harm's Healthier Hospital Initiative, has encouraged hospitals in countries around the world, including those in LMICs, to provide healthy, sustainable food to patients and employees. Leading by example, healthcare institutions have a unique opportunity to promote healthy eating and drinking behaviours in addition to their standard health-system function of acute-care service delivery. Take, for example, the case of smoking bans in US hospitals. In 1994, the Joint Commission on the Accreditation of Healthcare Organization banned smoking in hospitals and other medical facilities, representing the first US industry to ban smoking in the workplace. ${ }^{11}$ Though this ban was implemented to protect patients' health, subsequent studies showed that hospital employees also benefited. For example, hospital employees were more likely to quit smoking than their peers working in industries that did not adopt smoking bans. ${ }^{12}$

A ban on unhealthy foods in healthcare institutions could result in similar benefits: patients and employees exposed to healthy food and beverage choices on-site may be more likely to create similar healthy food environments in their homes. Following, for example, the taxes on unhealthy foods adopted by Mexico in 2014, such bans could cover sugar-sweetened beverages and non-essential foods with an energy density $\geq 275 \mathrm{kcal} / 1000 \mathrm{~g}$, including salty snacks, cakes and other processed foods. Bans on unhealthy foods (sugar-sweetened beverages and further restrictions on the calories per serving of prepackaged foods) have been proposed in public hospitals in the $\mathrm{UK},{ }^{13}$ but, to our knowledge, no bans exist in LMICs. The WHO recommends the elimination of unhealthy foods in the school environment, ${ }^{14}$ and we propose that similar recommendations should exist for healthcare institutions.

Healthcare institutions could also serve as a source of healthy foods for patients and employees. Kaiser Permanente, the largest non-profit healthcare system in the USA, has on-site farmers' markets at hospitals in four states. ${ }^{15}$ A survey of patrons to these farmers' markets conducted 
in 2010 found that $48 \%$ of weekly market users reported consuming 'a lot more' fruits and vegetables and 25\% of less frequent users, who visited just a few times per year, also reported eating 'a lot more' fruits and vegetables, ${ }^{15}$ thus demonstrating potential benefits of such a programme. Taking the farm-to-hospital movement a step further, Boston Medical Center recently opened a $650 \mathrm{~m}^{2}$ rooftop garden that is expected to produce $3175 \mathrm{~kg}$ of food this summer, which will feed into hospital cafeterias, patient meals and an on-site patient food pantry. ${ }^{16}$ While few evaluations of farm-to-hospital programmes have been conducted to date, a recent study found that US communities with healthcare institution-affiliated gardens had lower levels of obesity compared with the general US population (27\% vs $34 \%$ ) despite a similar demographic profile, ${ }^{17}$ indicating that such programmes are a promising approach to promoting health.

In the context of LMICs, there are emerging opportunities to leverage the widespread interest in urban agriculture among key global health players such as the Food and Agriculture Organisation ${ }^{18}$ to implement healthcare institution-affiliated gardens. Indeed, linkages between hospitals and urban gardens have already been documented in several Latin American cities, ${ }^{18}$ though we were unable to identify any evaluations of these programmes. In rural areas of LMICs (particularly South Asia and sub-Saharan Africa), several trials of homestead food production have been conducted and demonstrate significant positive impacts on dietary diversity though only a limited impact on stunting. ${ }^{19}$ A multisectoral solution that directly links food, agriculture and health systems should be explored as a complementary approach to addressing malnutrition.

On-site gardens and direct purchasing from local smallholder farmers would not only provide a source of healthy foods for the hospitals or clinics, but could also indirectly improve the livelihoods of the local community. For example, the primary goal of the Food and Agriculture Organisation's Purchase from Africans for Africa programme in Ethiopia, Malawi, Mozambique, Niger and Senegal is to promote food and nutrition security, but a potential co-benefit could be the prevention of obesity in schoolchildren as it encourages the consumption of non-processed, nutrient-dense foods. ${ }^{20}$ As part of the programme, Malawi smallholder farmers now provide staple grains, groundnuts, bananas and fish to 10 primary schools where enrolment has increased by $15 \% .{ }^{21}$ Similar programmes could be developed and tested in the context of health systems in LMICs.

In order to increase patient awareness and use of on-site food resources, healthcare institutions could adopt healthy food prescriptions written by physicians or community health workers that can be filled at on-site patient food pantries or farmers' markets. This would be an innovative approach to addressing both lack of nutrition knowledge and access to healthy foods among low-income patient populations. Primary care providers at the aforementioned Boston Medical Center, for example, write prescriptions for healthy foods that can be filled at their on-site patient food pantry, which in turn receives food from the hospital's rooftop garden. Low-income patients with HIV/AIDS, diabetes and obesity are among those who frequently benefit from this hospital service and are able to receive up to 4 days' worth of food for their families twice per month. ${ }^{22}$ Extending this to the context of LMICs, the World Food Programme's Food by Prescription programme provides food and nutrition counselling to patients with HIV and tuberculosis. The food basket typically consists of a staple, pulses, vegetable oil and, in some cases, micronutrient-fortified blended foods. ${ }^{23}$ Considering that these food baskets are often provided as a household ration, not just for the patient, ${ }^{24}$ adding nutrient-dense fruits and vegetables to the basket could expand this programme's benefits to include prevention of obesity and nutrition-related non-communicable diseases.

Hospitals in the USA and the UK have started to adopt innovative programmes such as farm-to-hospital initiatives, patient pantries and fruit and vegetable prescriptions to promote patient and employee wellness and address the growing burden of chronic diseases in these settings. Similarly, in the context of LMICs, forming strong links between local food, agriculture and health systems has the potential to address both ends of the malnutrition spectrum-and this is timely considering the urgent call by the global nutrition community for interventions addressing the dual burden of undernutrition and obesity and nutrition-related non-communicable diseases. ${ }^{4}$ Farm-to-hospital initiatives and healthy food prescriptions would create direct links between health and agriculture, and the involvement of clinical dietitians in the decision-making process would help ensure positive nutrition impacts. While all proposed actions may not be generalisable to severely resource-limited settings where governments are struggling to provide access to the most basic of healthcare needs, this preventive, food-based intervention that targets an underlying driver of many of the acute-care cases that require healthcare system access may, over the long term, reduce the health system burden. Strategic planning and goal setting help to ensure that key stakeholders are involved from multiple disciplines and that clear metrics of success are defined a priori. These activities should go hand-in-hand with the adoption of the proposed organisational policies and programme evaluation in order to monitor progress and impact.

Acknowledgements We would like to thank Aviva Musicus for her valuable guidance on the farm-to-hospital movement and healthy hospital initiatives in Boston and Christopher Sudfeld for his expert opinion on interventions to address undernutrition and overall feedback on the commentary.

Contributors LMJ and ALB have both contributed to the conception and design of this manuscript and to drafting and revising it.

Competing interests None declared.

Provenance and peer review Not commissioned; externally peer reviewed.

Open Access This is an Open Access article distributed in accordance with the Creative Commons Attribution Non Commercial (CC BY-NC 4.0) license, which 
permits others to distribute, remix, adapt, build upon this work non-commercially, and license their derivative works on different terms, provided the original work is properly cited and the use is non-commercial. See: http://creativecommons.org/ licenses/by-nc/4.0/

(c) Article author(s) (or their employer(s) unless otherwise stated in the text of the article) 2017. All rights reserved. No commercial use is permitted unless otherwise expressly granted.

\section{REFERENCES}

1. Food and Agriculture Organization. Chapter 3-the food system and factors affecting household food security and nutrition. Agriculture food and nutrition for Africa-a resource book for teachers of agriculture. In: Rome: Food and Agriculture Organization of the United Nations, 1997.

2. World Health Organization. Health systems strengthening glossary. Geneva: World Health Organization of the United Nations, 2017. http://www.who.int/healthsystems/hss_glossary/en/index5.html (accessed 3 Oct 2017).

3. Wang W, Alva S, Wang S, et al. Levels and trends in the use of maternal health services in developing countries. Calverton, Maryland, USA: United States Agency for International Development (USAID), 2011.

4. International Food and Policy Research Institute. Global nutrition report 2016: from promise to impact: ending malnutrition by 2030. Washington, DC: International Food Policy Research Institute, 2016.

5. Ramirez-Zea M, Kroker-Lobos MF, Close-Fernandez R, et al. The double burden of malnutrition in indigenous and nonindigenous Guatemalan populations. Am J Clin Nutr 2014;100:1644S-51.

6. Mozaffarian D, Hao T, Rimm EB, et al. Changes in diet and lifestyle and long-term weight gain in women and men. $N$ Engl $J$ Med 2011;364:2392-404.

7. Lassi ZS, Das JK, Zahid G, et al. Impact of education and provision of complementary feeding on growth and morbidity in children less than 2 years of age in developing countries: a systematic review. BMC Public Health 2013;13(Suppl 3):S13.

8. Iannotti LL, Lutter CK, Stewart CP, et al. Eggs in early complementary feeding and child growth: a randomized controlled trial. Pediatrics 2017;140:e20163459.

9. Green R, Sutherland J, Dangour AD, et al. Global dietary quality, undernutrition and non-communicable disease: a longitudinal modelling study. BMJ Open 2016;6:e009331.

10. Moran A, Krepp EM, Johnson Curtis C, et al. An intervention to increase availability of healthy foods and beverages in New York city hospitals: the healthy hospital food initiative, 2010-2014. Prev Chronic Dis 2016;13:E77.
11. Fee E, Brown TM. Hospital smoking bans and their impact. Am J Public Health 2004;94:185-85.

12. Longo DR, Brownson RC, Johnson JC, et al. Hospital smoking bans and employee smoking behavior: results of a national survey. JAMA 1996;275:1252-7.

13. Donnelly L. NHS set to ban sale of sugary drinks and fatty snacks in hospital cafes and canteens: The Daily Telegraph, 2017.

14. World Health Organization. Report of the Commission on ending childhood obesity. Geneva: World Health Organization, 2016.

15. Cromp D, Cheadle A, Solomon L, et al. Kaiser Permanente's farmers' market program: description, impact, and lessons learned. J Agr Food Syst Community Dev 2012;2:29-36.

16. Viall T. Boston Medical Center grows first hospital-based rooftop farm in Massachusetts Boston: Boston Medical Center, 2017. https:// www.bmc.org/news/press-releases/2017/07/13/boston-medicalcenter-grows-first-hospital-based-rooftop-farm (accessed 28 Aug 2017).

17. George DR, Rovniak LS, Kraschnewski JL, et al. A growing opportunity: community gardens affiliated with us hospitals and academic health centers. Prev Med Rep 2015;2:35-9.

18. Food and Agriculture Organization of the United Nations. Thomas $\mathrm{G}$, edn. Growing greener cities in Latin America and the Caribbean. Rome: Food and Agriculture Organization of the United Nations, 2014.

19. Haselow NJ, Stormer A, Pries A. Evidence-based evolution of an integrated nutrition-focused agriculture approach to address the underlying determinants of stunting. Matern Child Nutr 2016;12(Suppl 1):155-68.

20. Food and Agriculture Organization of the United Nations. Scaling-up purchase from Africans for Africa: family farmers supply nutritious meals for school children. Rome: Food and Agriculture Organization of the United Nations, 2014.

21. World Food Programme. Improving links between smallholder farmers and school feeding programmes 27 August 2014. https:// www.wfp.org/purchase-progress/news/blog/p4p-improves-linksbetween-small-scale-farmers-and-school-feeding-progra (accessed 28 Sep 2015).

22. Boston Medical Center. Preventive food pantry. Boston, MA: Boston Medical Center, 2017. https://www.bmc.org/programs/preventivefood-pantry (accessed 29 Aug 2017).

23. World Food Programme. The WFP food basket Rome: world food programme. 2017 https://www.wfp.org/food-assistance/kind-foodassistance/wfp-food-basket (accessed 28 Aug 2017).

24. de Pee S, Grede N, Mehra D, et al. The enabling effect of food assistance in improving adherence and/or treatment completion for antiretroviral therapy and tuberculosis treatment: a literature review. AIDS Behav 2014;18(Suppl 5):531-41. 